\title{
A MULTI-DIRECIONALIDADE DA TRANSFERÊNCIA \\ DA DURAÇÃo VOCÁlICA DO PORTUGUÊS COMO L3 PARA A L1 (ESPANHOL) E A L2 (INGLÊS): UM ESTUDO LONGITUDINAL
}

\section{MULTI-DIRECTIONALITY IN THE TRANSFER OF VOWEL DURATION FROM L3 PORTUGUESE TO L1 SPANISH AND L2 ENGLISH:} A LONGITUDINAL STUDY

\author{
Letícia Pereyron | Lattes | leticiapereyron@gmail.com \\ Escola Superior de Propaganda e Marketing | ESPM-Sul
}

Ubiratã Kickhöfel Alves | Lattes | ukalves@gmail.com Universidade Federal do Rio Grande do Sul | CNPq

Resumo: Este trabalho, à luz da Teoria dos Sistemas Dinâmicos, Adaptativos Complexos (BECKNER et al., 2009; DE BOT et al., 2013; SILVA, 2014), visa a investigar a premissa de que uma mudança em qualquer parte do sistema linguístico pode gerar alteração nas suas outras partes componentes. A partir desta premissa, conduziu-se um estudo de cunho longitudinal. $\mathrm{O}$ estudo contou com um aprendiz trilíngue, residente no Brasil, falante do espanhol (variedade mexicana) como L1, inglês como L2 e português como L3. Tal estudo contou com instrução formal, de base comunicativa e articulatória, sobre sons vocálicos do Português Brasileiro (L3). Através da instrução formal, visou-se a causar uma modificação acelerada no sistema fonético-fonológico de L3 do aprendiz, para se verificar se tal modificação ocasionaria efeitos sobre a sua L1 (Espanhol) e a sua L2 (Inglês). Verificou-se, para esse fim, a duração das vogais tônicas nas três línguas. A instrução deu-se ao longo de 4 meses, com uma aula de 90 minutos por semana. As coletas contaram com listas de palavras nas três línguas referidas, e ocorreram anteriormente ao período de instrução, durante (a cada 4 semanas) e ao término da instrução formal, de modo a totalizar 5 coletas com o participante. Os achados deste estudo longitudinal evidenciaram que as alterações nas durações das vogais do português (L3), aceleradas pela instrução fornecida, causaram alterações nas durações vocálicas (absoluta e relativa) das demais línguas, devido à interconexão dos sistemas do falante multilíngue.

Palavras-chave: Multilinguismo; Transferência linguística; Sistemas Adaptativos Complexos. 
Abstract: Following a Dynamic, Complex-Adaptive System account (BECKNER et al., 2009; DE BOT et al., 2013; SILVA, 2014), this study aims to address the assumption that changes in an additional language system (such as the L3) may account for the co-ocurrence of changes in the previously learned language systems (such as the L1 and the L2). Departing from this assumption, a longitudinal study was conducted with a Mexican learner (L1 Spanish) who had been residing in Brazil (L2: English; L3: Brazilian Portuguese) at the time of the study. The instruction consisted of weekly 90-minute classes and took place throughout 4 months. The data collections consisted of recordings of word lists in the three languages. The first recording was conducted before the instructional period, the next three recordings were conducted after every four classes, and the fifth recording was conducted at the end of the experiment, totaling 5 recordings. The findings of the longitudinal study provided evidence to the premise that alterations of vowel durations in the L3 system (Brazilian Portuguese), accelerated by formal instruction, may cause alterations in the absolute and relative durations of the vowels of the other languages, due to the interrelation among the language systems of this multilingual speaker.

Key-words: Multilingualism; Language transfer; Complex Adaptive systems.

\section{Introdução}

O presente trabalho visa a investigar, à luz da Teoria dos Sistemas Dinâmicos, Adaptativos Complexos (BECKNER et al., 2009; DE BOT et al., 2013, SILVA, 2014), a premissa de que uma mudança em um sistema linguístico pode gerar alteração nos demais sistemas linguísticos de um indivíduo, inclusive em línguas já previamente aprendidas. Com base nessa premissa, conduziu-se um estudo de cunho longitudinal que contou com um aprendiz trilíngue falante do espanhol (variedade mexicana) como L1, inglês como L2 e português como L3. Durante um período de 4 meses, foi oferecido instrução formal de base comunicativa e articulatória sobre os sons vocálicos $[\varepsilon]$, como em "peça", e [0], como em "copo", presentes na L3, mas ausentes na L1. Partiu-se da hipótese de que a instrução intensiva de tais sons poderia exercer efeitos sobre as durações vocálicas tanto da L1, quanto da L2, devido à completa interconexão entre os sistemas. Dado que as vogais tônicas do português apresentam durações maiores do que no espanhol (SANTOS, 2014; SANTOS; RAUBER, 2016), previu-se que a instrução levaria os aprendizes a produzirem vogais mais longas não somente na L1, mas também em inglês (L2), dado que a duração das vogais mais longas nesta língua também representa um problema para hispânicos (FEIDEN et al., 2016; PEREYRON, 2017). 
A metodologia do presente trabalho foi motivada pela premissa de que dados individuais e longitudinais de aprendizagem de línguas adicionais parecem ser mais ricos em termos de informação e de explanação dos processos de desenvolvimento fonético-fonológico na L2, conforme propõem emergentistas (LARSEN-FREEMAN, 1997; 2013; DE BOT; LOWIE; VERPOOR, 2007; LIMA JÚNIOR, 2016a, b). Nesse sentido, o estudo contou com 5 coletas de dados (uma antes, três durante e uma após a instrução), que consistiam na leitura de palavras nas três línguas referidas, inseridas em frases-veículo. O tratamento acústico dos dados deste experimento ocorreu através do programa Praat (BOERSMA; WEENINK, 2015). Dessa forma, houve a oportunidade de acompanhar o desenvolvimento individual desse participante trilíngue, de modo que fossem traçadas suas curvas desenvolvimentais, conforme sugerem os autores supracitados adeptos à Teoria dos Sistemas Dinâmicos.

Com vistas a atender ao propósito desta pesquisa, o de verificar a premissa de que uma alteração em um sistema pode exercer efeitos sobre os outros, este trabalho está organizado em 5 seções. A seguir, na seção 2, serão apresentados os pressupostos teóricos, seguidos pela Metodologia, que compõe a seção 3. Os resultados, referentes aos valores de duração absoluta e relativa das vogais tônicas nas três línguas, serão apresentados na seção 4, e a conclusão, na seção 5.

\section{Pressupostos teóricos}

Larsen-Freeman (1997; 2006; 2011; 2013), Ellis (2011) e De Bot et al. (2013), entre outros analisam a língua como um Sistema Adaptativo Complexo (CAS). Nesse sentido, conceber a língua como CAS envolve admitir múltiplos agentes como formadores do próprio sistema linguístico. A complexidade do sistema, entretanto, não resulta dos diversos agentes envolvidos no desenvolvimento linguístico, mas sim das inter-relações que tais múltiplos agentes estabelecem uns com os outros.

Outra propriedade dos Sistemas Adaptativos Complexos é a dinamicidade, o que implica mudança através do tempo. Em sistemas complexos, o resultado do desenvolvimento ao longo do tempo não pode ser calculado com exatidão, não por falta de ferramentas certas, mas porque as variáveis que fazem parte desse sistema interagem e se modificam constantemente. $O$ desenlace dessas variáveis, a menos que fizessem parte de um sistema simples, não pode ser resolvido analiticamente. A trajetória dinâmica, nesse sentido, deve incluir as interações frequentes e recorrentes do próprio sistema e, dessa forma, não há equação que ofereça um valor exato do sistema (DE BOT; LOWIE; VERSPOOR, 2007). 
De Bot e Larsen-Freeman (2011) afirmam que, em um sistema dinâmico, todas as partes de um dado sistema estão conectadas a todas as outras partes. Conceber a língua como um sistema dinâmico significa considerar que todos os subsistemas - o sistema lexical, o sistema fonológico e o sistema sintático - estão inter-relacionados e, além disso, uma alteração no sistema fonético-fonológico de uma dada língua poderá resultar em mudanças nas demais línguas do indivíduo, vindo a alterar as demais línguas do falante multilíngue.

Cabe ressaltar, ainda, outra propriedade desses sistemas: a não-linearidade, uma vez que o desenvolvimento linguístico ocorre das interações entre agentes, o que implica resultados imprevisíveis e não-lineares. A não-linearidade também ocorre no âmbito das influências interlinguísticas. A perspectiva que considera o sistema linguístico como CAS postula que as línguas influenciam umas às outras, tanto a mais forte e mais dominante, quanto a mais fraca (FRANCESCHINI, 1999; CENOZ, 2001; BRITO, 2011; GROSJEAN, 2013). A noção de que a transferência está atribuída à influência unidirecional da língua materna, uma vez que aprendizes cometem erros linguísticos que não se referem a suas L1s, é rejeitada. A transferência linguística é, no mínimo, bidirecional.

Considerando a língua, também, como CAS, Herdina e Jessner (2002) aplicam a TSD ao estudo do desenvolvimento multilíngue, de modo a sugerirem que o multilinguismo compõe um sistema dinâmico, composto de sistemas repletos de agentes, que interagem entre si e, assim, geram crescimento. Essas autoras consideram que os sistemas dos falantes bi- ou multilíngues estão inter-relacionados e dependem uns do outros. Dessa maneira, não é um sistema que influencia o outro de uma maneira linear ou "um para um"; de fato, o sistema linguístico em desenvolvimento é o resultado da inter-relação estabelecida pelos referidos sistemas componentes.

Adicionalmente, Larsen-Freeman (2011), De Bot; Verspoor; Lowie (2007) e Larsen-Freeman; Cameron (2008) e, em contexto brasileiro, Lima Júnior (2016a, b), sugerem uma análise individualizada do desenvolvimento da fala do aprendiz devido à grande dinamicidade e complexidade que compõem o sistema linguístico. Uma vez que um sistema dinâmico complexo e adaptativo é influenciável por uma grande gama de variáveis e é altamente sensível a um estágio inicial, cada indivíduo apresenta, portanto, um sistema de complexidade e singularidades tais que são dignas de ser analisadas individualmente, através da observação do desenvolvimento linguístico do indivíduo ao longo do tempo. Estudos longitudinais e estudos de caso permitem conexões a serem feitas através de níveis e escalas de tempo. Além disso, segundo Barboza (2013), estudos longitudinais 
permitem uma descrição do desenvolvimento dinâmico, característica intrínseca aos sistemas adaptativos complexos. O modelo longitudinal apresenta-se como capaz de indicar a variação no desenvolvimento.

Nesse sentido, vem a ser de suma importância um estudo longitudinal, que inclua o papel da interação entre variáveis e, principalmente, que investigue a premissa de que uma mudança em uma das línguas (L3) causa, de fato, alteração nas outras línguas (L1 e L2). Além disso, os modelos dinâmicos apresentam como meta a especificação de como as mudanças dos estados dos sistemas ocorrem. Nesse sentido, modelos dinâmicos têm por objetivo explicar as mudanças temporais. Van Gelder; Port (1995), ao se referirem à premissa de que processos cognitivos se desenvolvem ao longo do tempo real, definem 'tempo' como uma quantidade contínua medida por números reais, e afirmam, ainda, que para cada ponto no tempo há um estado do sistema cognitivo.

Sob essa mesma ótica, a que retoma a noção de 'período', Lima Júnior (2016a, b) analisa o desenvolvimento fonológico da língua adicional com um sistema dinâmico, adaptativo complexo. O autor sugere que a Teoria dos Sistemas Adaptativos Complexos dá conta não apenas de processos linguísticos, mas de sistemas/processos naturais do mundo. Com uma base teórica ancorada em Larsen-Freeman (1997), Herdina; Jessner (2002), De Bot; Lowie; Verspoor (2007), De Bot (2008) e Larsen-Freeman; Cameron (2008), Lima Júnior (2016a, b) propõe uma análise individualizada e longitudinal do desenvolvimento fonológico dos aprendizes, já que, dessa forma, é possível retratar o processo em contínua mudança e não apenas um retrato (estágio) em que se encontra a fala do participante no momento da coleta. Conforme aponta o autor, a análise transversal e aglutinada apresenta-se limitada quando comparada com a análise longitudinal e individual, pela natureza complexa e dinâmica do processo de desenvolvimento de uma LA. Além disso, a complexidade e dinamicidade desse processo está intimamente ligada à não-linearidade, que também é mais bem retratada em estudos individuais e longitudinais.

\section{0 estudo}

\subsection{Objetivo, hipótese e operacionalização}

O presente estudo teve como objetivo geral verificar a premissa dinâmica de que uma mudança em um componente do sistema linguístico pode modificar os demais componentes. Mais especificamente, o presente estudo longitudinal investiga o papel da intervenção intensiva no desenvolvimento da L3 e seus efeitos sobre os sistemas da L1 e da 
L2 do aprendiz trilíngue, no que diz respeito aos valores de duração absoluta e relativa das vogais tônicas das palavras investigadas nas três línguas.

A hipótese é a de que a alteração, ao longo do tempo, provinda da instrução da L3 (que leva o aprendiz a abandonar o padrão duracional de sua L1 e passar a produzir vogais mais longas, como no Português) deve modificar a L1 e a L2, devido à completa interconexão entre os sistemas. Dessa forma, a produção das vogais abertas do português $[\mathcal{E}]$, como em "peça" e [o], como em "copo", acelerada pela instrução, poderá causar alterações nos valores de duração tanto absoluta quanto relativa das vogais abertas do inglês, sobretudo [E], como em "set", [æ], como em "cat", [॰], como em "often” e [a], como em "soccer", mesmo sendo essas últimas distintas das vogais abertas do português, e também nos valores das durações das vogais [a], como em "paco", [e], como em "pepa”, e [o], como em "coche" do espanhol. Conforme já explicado, espera-se que a instrução do português possa causar durações mais longas nas vogais da L2 e também da própria L1, dado que as vogais do português tendem a ser mais longas do que as do Espanhol (SANTOS, 2014; SANTOS; RAUBER, 2016).

Quanto à operacionalização, foram comparadas as curvas desenvolvimentais dos sistemas vocálicos das línguas do aprendiz trilíngue longitudinalmente: (uma semana) antes do início do período de instrução, ao longo do período de instrução (a cada quatro semanas) e ao fim de todas as sessões de instrução, com vistas a verificar se houve possíveis alterações nas durações vocálicas, em cada um dos sistemas, ao longo de todo o período de investigação ${ }^{1}$.

\subsection{O informante}

O estudo longitudinal (que transcorreu de abril a agosto de 2015) contou com um participante de nacionalidade mexicana, com 38 anos de idade e aluno de Doutorado do Programa de Pós-Graduação em Biologia em uma instituição privada de ensino superior de Porto Alegre. O aluno demonstrou forte interesse e motivação para aprender o português. Seu contato inicial com a língua portuguesa havia começado 5 meses antes da sua vinda ao Brasil, através dos cursos Duolingo e Babel. ${ }^{2} \mathrm{O}$ aprendiz mexicano convive com outros falantes de espanhol na sua residência, mas afirma usar a língua portuguesa em

\footnotetext{
${ }^{1}$ Para o estudo completo, veja Pereyron (2017), que apresenta, além das durações, as descrições das alterações em termos de altura e anterioridade/posterioridade que as vogais das três línguas do participante sofreram.

2 Ambos os cursos são oferecidos na internet, gratuitamente. Sua metodologia insere jogos e outras atividades interativas.
} 
contexto acadêmico, como nas aulas do Doutorado. O participante residia há dois meses em Porto Alegre quando iniciou o presente estudo. Quanto ao inglês, o aprendiz informou que o adquiriu de forma autônoma, lendo artigos e traduzindo músicas. Ademais, possui nível de proficiência B1 na língua inglesa de acordo com o resultado obtido no Oxford Online Placement Test ${ }^{3}$, sendo, portanto, um aprendiz de grau intermediário-avançado.

\subsection{Palavras e Instrumentos de coleta}

Para fins da presente pesquisa, foram formulados três instrumentos de leitura: uma sequência de frases-veículo com palavras na língua espanhola, uma sequência com palavras na língua portuguesa e outra, com palavras em inglês. Os vocábulos dos instrumentos em português e em espanhol são dissilábicos (como, por exemplo, 'faca' em português, e 'pepa', em espanhol) e trissilábicos (como 'sucata', em português, e 'machete', em espanhol). Optou-se por palavras com duas e três sílabas para atender ao critério de que as palavras tivessem que ser bastante frequentes ${ }^{4}$ na língua a ser lida, visto que a variável referente à frequência de uso foi controlada. Para tal propósito, apenas palavras dissilábicas não foram suficientes; assim, foram inseridas as palavras com três sílabas e também bastante frequentes, como, por exemplo, a palavra 'alface'.

A vogal analisada foi a tônica, localizada na primeira sílaba da palavra dissilábica (como, por exemplo, a vogal 'a' em 'fato)', ou na segunda sílaba da palavra de três silabas (como, por exemplo, a vogal 'a' em 'sucata'). Para ambas as línguas foram utilizadas as plosivas $[\mathrm{p}, \mathrm{t}, \mathrm{k}] \mathrm{e} / \mathrm{ou}$ as fricativas e africadas $\left[\mathrm{s}, \int, \mathrm{f}, \mathrm{f}\right]$ como contexto antecedente e seguinte. Os contextos antecedentes e seguintes da vogal tônica eram surdos ${ }^{5}$, de modo a não causar um alongamento da referida vogal devido ao vozeamento da consoante precedente ou seguinte (cf. ALVES, 2015). Foram investigadas as cinco vogais do espanhol [a, $\mathrm{e}, \mathrm{i}, \mathrm{o}, \mathrm{u}]$ e as sete vogais orais do português $[\mathrm{a}, \mathcal{E}, \mathrm{e}, \mathrm{i}, \mathrm{o}, \mathrm{o}, \mathrm{u}]$. Para cada vogal, foram

\footnotetext{
${ }^{3}$ O Oxford Online Placement Test é um teste online da Oxford University Press, que mede tanto a habilidade de compreensão da gramática da língua inglesa, quanto a compreensão oral. Os testes podem ser comprados em www.oxfordenglishtesting.com. Para maiores detalhes acerca do teste, conferir Purpura (2007).

${ }^{4}$ Um critério tomado na escolha das palavras em língua inglesa e portuguesa foi o fato de essas palavras não serem cognatas com a língua espanhola. Além disso, a frequência das palavras foi verificada através do banco de dados corpus brasileiro do LAEL (Linguística Aplicada e Estudos da Linguagem) da PUCSP, para as palavras em português. Já as palavras em inglês tiveram a frequência verificada no site www.clearpond. com. Quanto às palavras em espanhol, essas foram verificadas através do Espal - Spanish lexical database.

${ }^{5}$ Houve apenas uma exceção com referência ao vozeamento. Trata-se da palavra 'beco', em português, que apresenta contexto antecedente vozeado, pois não foi encontrada uma palavra dissilábica com a vogal [e] e contexto antecedente surdo que não fosse cognata.
} 
apresentadas seis palavras (6 types), com três repetições (3 tokens), de modo a serem obtidas dezoito produções de cada vogal em cada língua. Além disso, não foram incluídas palavras cognatas com o espanhol no instrumento em português, a fim de não induzir o informante falante de espanhol como $\mathrm{L} 1$ a acessar sua língua nativa. $\mathrm{O}$ mesmo procedimento foi realizado para o espanhol: o instrumento contou com seis palavras para cada vogal, três sendo dissilábicas e três trissilábicas, repedidas três vezes, totalizando dezoito produções, por participante, para cada vogal.

As palavras foram inseridas em frases-veículos (Diga "palavra-alvo"), apresentadas em slides, como "diga tosse" e "diga pipoca", em português, e "diga coche" e "diga machaca", em espanhol; dessa forma, a taxa de elocução (velocidade de fala) pôde ser controlada. A lista de palavras do espanhol contou com 105 tokens, dos quais 90 eram palavras-alvo e 15 distratores; por sua vez, a lista de palavras do português contou com 145 tokens, dos quais 126 eram palavras-alvo e 19, distratores.

Para a formulação do instrumento em inglês, foram utilizadas palavras monossilábicas, como em 'cat', e dissilábicas, como em 'apple', uma vez que esses padrões são mais frequentes na língua. Foram investigadas as nove vogais do inglês norte-americano, conforme o estudo de Blank (2013): [a, æ, E, I, i, o,, , $\Lambda$, u]. Para cada vogal, também utilizaram-se as plosivas surdas $[\mathrm{p}, \mathrm{t}, \mathrm{k}]$, fricativas e africadas surdas $\left[\mathrm{s}, \int, \mathfrak{f}, \mathrm{f}\right]$, como contextos antecedentes e seguintes. Optou-se por apenas essas obstruintes, e não nasais ou líquidas, para uma análise acústica mais clara, uma vez que essas consoantes se mostram mais visualmente perceptíveis nos espectrogramas. As consoantes vozeadas também foram excluídas como contexto antecedente ou seguinte, por promoverem um alongamento da vogal (ALVES, 2015). Os critérios empregados foram os mesmos dos outros instrumentos; dessa forma, o instrumento em inglês também foi composto por palavras inseridas em frases-veículo ("Say ”), contou com 6 types por vogal, 3 repetições, totalizando 18 tokens por vogal. Quanto ao número de palavras do instrumento em inglês, a leitura incluiu 186 tokens, dos quais 24 eram distratores. Além disso, todas as palavras foram inseridas, nos respectivos instrumentos, em ordem aleatória.

\subsection{As coletas}

As coletas foram realizadas em uma sala silenciosa, onde apenas o participante e a primeira autora deste trabalho estavam presentes. Ao participante, foi solicitada a leitura das palavras dos três instrumentos da presente pesquisa. A primeira coleta foi realizada antes do período de instrução e as seguintes coletas ocorreram a cada 4 semanas durante 
os meses de instrução, de modo que a quinta coleta ocorreu ao final desse período. As coletas foram realizadas com pausas de 5 minutos entre as leituras dos instrumentos. $\mathrm{O}$ ordenamento de aplicação dos instrumentos em espanhol e em português deste estudo foi realizado de forma alternada, a fim de que o participante não se acostumasse com a ordem dos instrumentos de leitura. Além disso, procurou-se iniciar com o instrumento nas línguas que estavam ativadas, ou seja, espanhol e português. Desse modo, a leitura do inglês sempre foi a última a ser realizada, já que não estava sendo utilizada oralmente durante o período de instrução. O software utilizado para a gravação de áudio dos participantes foi o Audacity ${ }^{6}$, e a gravação foi realizada em um computador Sony Vaio, com um microfone Sony, modelo ECM XM1, ligado diretamente no computador. Todo o material acústico foi salvo em arquivo wav, com taxa de amostragem de 44.100 Hertz.

\subsection{A instrução}

A instrução, com base no ensino de pronúncia de cunho comunicativo (cf. CELCEMURCIA et al., 1996), além de voltada ao desenvolvimento de aspectos de pronúncia não em contexto isolado, mas integrado a funções comunicativas, teve por objetivo diminuir as dificuldades dos falantes nativos do espanhol na produção vocálica em português, como, por exemplo, na produção das vogais médias baixas. Teve, também, o objetivo de acelerar o processo de desenvolvimento fonético-fonológico do participante, para que, no curto intervalo de quatro meses, pudessem ser vistas modificações na produção das vogais da L3 do aprendiz. Desse modo, ao se enfatizarem os sons [ $\varepsilon]$ e [o] inexistentes na língua espanhola, mas existentes na portuguesa, pretendeu-se forçar mudanças no sistema de L3 e verificar se tais mudanças alterariam os outros sistemas de L1 e L2. As sessões foram ministradas em 16 encontros com duração de uma hora e 30 minutos cada, sendo que as 8 primeiras sessões ocorreram no curso de português para estrangeiros (com foco em escrita e leitura), juntamente a outros alunos que faziam parte da instrução. Em seguida, por mais 8 sessões, o participante mexicano participou da instrução de forma individual, cujas aulas aconteceram na biblioteca da instituição.

A seguir, serão apresentados os resultados, em termos de duração absoluta e rela$\operatorname{tiva}^{7}$, referentes às vogais da língua de instrução, o português, para a verificação de uma possível alteração em termos de duração das vogais do espaço acústico da L3 do informante. Em seguida, serão apresentados os resultados referentes às durações das vogais da

\footnotetext{
${ }^{6}$ Software livre. Download gratuito em www.audacity.sourceforge.net.

${ }^{7}$ Em Pereyron (2017), encontra-se uma descrição completa do estudo em questão, em que os valores formânticos também são apresentados.
} 
L2 do aprendiz, o inglês, para uma verificação de possíveis alterações do sistema vocálico, sobretudo das vogais mais baixas, dessa língua. Finalmente, serão apresentados os resultados referentes à L1 do aprendiz, o espanhol, com a finalidade de verificação da premissa que postula que uma alteração em um dos sistemas, no presente caso, o português, possa vir a alterar todo o restante, inclusive o sistema materno.

\section{Resultados}

\subsection{O português}

A instrução intensiva, juntamente à imersão em contexto de L3, ocasionou uma produção mais abaixada das vogais médias-baixas anteriores da L3 do aprendiz a partir da terceira coleta, conforme é demonstrado em Pereyron (2017), no que diz respeito aos formantes. A produção (e a percepção) das vogais médias anteriores de forma mais baixa vão ao encontro do que afirma Lindblom (1986), com relação à melhor percepção das vogais anteriores do que as vogais posteriores.

Nesse sentido, a realização mais aberta dessas vogais tende a condicionar um alongamento justamente devido à maior abertura da mandíbula para a realização. No entanto, todo o sistema vocálico demonstra maior duração a partir da terceira coleta. A Tabela 1 a seguir apresenta os valores das médias da duração vocálica absoluta do participante do estudo longitudinal, ao longo do período de instrução. Os valores de durações relativas são apresentados na Tabela 2. As células em amarelo correspondem às realizações mais longas pelo participante.

Tabela 1. Médias (em milissegundos) e Desvios-Padrão das durações absolutas das vogais do português produzidas pelo participante do estudo longitudinal ( $\mathrm{n}$. de cada vogal $=18$ por coleta, total de 126 vogais por coleta)

\begin{tabular}{c|c|c|c|c|c|c|c}
\hline & {$[\mathrm{a}]$} & {$[\varepsilon]$} & {$[\mathrm{e}]$} & {$[\mathrm{i}]$} & {$[\mathrm{]}]$} & {$[\mathrm{o}]$} & {$[\mathrm{u}]^{8}$} \\
\hline Coleta 1 & 142,9 & 129,2 & 125,7 & 97,2 & 135,3 & 135,5 & 117,2 \\
& $\mathrm{DP}: 13,5$ & $\mathrm{DP}: 16,95$ & $\mathrm{DP}: 20,4$ & $\mathrm{DP}: 22,8$ & $\mathrm{DP}: 14,3$ & $\mathrm{DP}: 13,0$ & $\mathrm{DP}: 13,0$ \\
\hline Coleta 2 & 167,8 & 163,05 & 152,5 & 113,9 & 152,8 & 144,2 & 126,2 \\
& $\mathrm{DP}: 33,4$ & $\mathrm{DP}: 26,95$ & $\mathrm{DP}: 152,55$ & $\mathrm{DP}: 20,0$ & $\mathrm{DP}: 28,05$ & $\mathrm{DP}: 20,8$ & $\mathrm{DP}: 26,2$ \\
\hline Coleta 3 & 184,8 & 182,9 & 169,4 & 126,9 & 167,9 & 164,1 & 128,05 \\
& $\mathrm{DP}: 18,03$ & $\mathrm{DP}: 16,85$ & $\mathrm{DP}: 22,5$ & $\mathrm{DP}: 20,4$ & $\mathrm{DP}: 27,8$ & $\mathrm{DP}: 17,3$ & $\mathrm{DP}: 19,3$ \\
\hline Coleta 4 & 168,8 & 171,8 & 168,2 & 112,7 & 157,3 & 156,2 & 128,4 \\
& $\mathrm{DP}: 21,0$ & $\mathrm{DP}: 15,3$ & $\mathrm{DP}: 21,05$ & $\mathrm{DP}: 24,7$ & $\mathrm{DP}: 20,0$ & $\mathrm{DP}: 19,4$ & $\mathrm{DP}: 21,9$ \\
\hline Coleta 5 & 165 & 165,9 & 160,4 & 103,6 & 153,5 & 146,7 & 119,8 \\
& $\mathrm{DP}: 18,0$ & $\mathrm{DP}: 17,8$ & $\mathrm{DP}: 20,3$ & $\mathrm{DP}: 32,4$ & $\mathrm{DP}: 22,4$ & $\mathrm{DP}: 15,2$ & $\mathrm{DP}: 21,15$ \\
\hline
\end{tabular}


Tabela 2. Médias (em porcentagens) e Desvios-Padrão das durações relativas ${ }^{8}$ das vogais do português produzidas pelo participante do estudo longitudinal (n. de cada vogal $=18$ por coleta, total de 126 vogais por coleta)

\begin{tabular}{c|c|c|c|c|c|c|c}
\hline Dissílabos & {$[\mathrm{a}]$} & {$[\varepsilon]$} & {$[\mathrm{e}]$} & {$[\mathrm{i}]$} & {$[\mathrm{O}]$} & {$[\mathrm{o}]$} & {$[\mathrm{u}]$} \\
\hline Coleta 1 & 15,88 & 13,96 & 16,09 & 11,31 & 15,10 & 14,36 & 12,32 \\
& $\mathrm{DP}: 1,04$ & $\mathrm{DP}: 1,63$ & $\mathrm{DP}: 2,5$ & $\mathrm{DP}: 1,4$ & $\mathrm{DP}: 1,5$ & $\mathrm{DP}: 1,22$ & $\mathrm{DP}: 0,95$ \\
\hline Coleta 2 & 16,17 & 15,56 & 18,85 & 12,20 & 16,11 & 13,98 & 13,53 \\
& $\mathrm{DP}: 2,7$ & $\mathrm{DP}: 2,06$ & $\mathrm{DP}: 2,87$ & $\mathrm{DP}: 1,68$ & $\mathrm{DP}: 3,0$ & $\mathrm{DP}: 1,49$ & $\mathrm{DP}: 1,65$ \\
\hline Coleta 3 & 18,92 & 18,55 & 20,30 & 13,75 & 18,19 & 17,77 & 13,21 \\
& $\mathrm{DP}: 1,42$ & $\mathrm{DP}: 1,72$ & $\mathrm{DP}: 2,75$ & $\mathrm{DP}: 2,41$ & $\mathrm{DP}: 2,6$ & $\mathrm{DP}: 2,42$ & $\mathrm{DP}: 1,84$ \\
\hline Coleta 4 & 16,49 & 16,48 & 18,67 & 13,20 & 16,83 & 17,02 & 12,22 \\
& $\mathrm{DP}: 2,66$ & $\mathrm{DP}: 1,4$ & $\mathrm{DP}: 2,26$ & $\mathrm{DP}: 1,36$ & $\mathrm{DP}: 2,16$ & $\mathrm{DP}: 1,67$ & $\mathrm{DP}: 2,15$ \\
\hline Coleta 5 & 16,50 & 17,03 & 19,28 & 10,85 & 17,05 & 16,38 & 12,36 \\
& $\mathrm{DP}: 1,23$ & $\mathrm{DP}: 1,45$ & $\mathrm{DP}: 2,16$ & $\mathrm{DP}: 2,15$ & $\mathrm{DP}: 2,16$ & $\mathrm{DP}: 1,67$ & $\mathrm{DP}: 1,33$ \\
\hline Trissílabos & {$[\mathrm{a}]$} & {$[\varepsilon]$} & {$[\mathrm{e}]$} & {$[\mathrm{i}]$} & {$[\mathrm{O}]$} & {$[\mathrm{o}]$} & {$[\mathrm{u}]$} \\
\hline Coleta 1 & 14,27 & 13,24 & 11,61 & 9,01 & 12,85 & 13,31 & 11,87 \\
& $\mathrm{DP}: 1,13$ & $\mathrm{DP}: 1,8$ & $\mathrm{DP}: 1,3$ & $\mathrm{DP}: 2,53$ & $\mathrm{DP}: 1,15$ & $\mathrm{DP}: 1,4$ & $\mathrm{DP}: 1,07$ \\
\hline Coleta 2 & 16,67 & 15,30 & 12,53 & 9,93 & 13,44 & 13,04 & 11,72 \\
& $\mathrm{DP}: 2,16$ & $\mathrm{DP}: 2,22$ & $\mathrm{DP}: 1,5$ & $\mathrm{DP}: 1,8$ & $\mathrm{DP}: 1,56$ & $\mathrm{DP}: 1,93$ & $\mathrm{DP}: 2,5$ \\
\hline Coleta 3 & 17,62 & 17,57 & 14,62 & 11,54 & 14,70 & 14,66 & 12,62 \\
& $\mathrm{DP}: 0,92$ & $\mathrm{DP}: 1,74$ & $\mathrm{DP}: 1,45$ & $\mathrm{DP}: 1,35$ & $\mathrm{DP}: 1,65$ & $\mathrm{DP}: 1,27$ & $\mathrm{DP}: 2,1$ \\
\hline Coleta 4 & 15,40 & 15,35 & 14,26 & 8,58 & 12,66 & 12,92 & 11,71 \\
& $\mathrm{DP}: 2,24$ & $\mathrm{DP}: 1,93$ & $\mathrm{DP}: 1,8$ & $\mathrm{DP}: 2,33$ & $\mathrm{DP}: 0,76$ & $\mathrm{DP}: 1,85$ & $\mathrm{DP}: 1,42$ \\
\hline Coleta 5 & 15,58 & 15,91 & 13,85 & 9,58 & 13,35 & 13,39 & 12 \\
& $\mathrm{DP}: 1,7$ & $\mathrm{DP}: 1,9$ & $\mathrm{DP}: 2,0$ & $\mathrm{DP}: 3,7$ & $\mathrm{DP}: 1,7$ & $\mathrm{DP}: 1,63$ & $\mathrm{DP}: 2,54$ \\
\hline
\end{tabular}

Os valores mais baixos (ou seja, as durações vocálicas mais curtas) são sempre encontrados na primeira coleta do participante deste estudo, o que representa o período pré-instrucional, de modo a indicar que o sistema vocálico ainda se encontrava no início do desenvolvimento, visto que o participante já tinha contato com o português neste período. Embora esses valores sejam os mais baixos, a duração vocálica do aprendiz já pode estar mostrando alterações nessa fase, devido à exposição ao sistema alvo, se comparada à duração do sistema vocálico materno do participante, que dispõe de 5 vogais dentre as 7 vogais do português.

Os valores da segunda, quarta e quinta coletas mostram aproximação entre si, mas se distinguem da terceira coleta, que apresenta valores bastante altos, e da primeira, que apresenta os valores mais baixos, o que traz uma noção de não-linearidade ao desenvolvimento do sistema, característica intrínseca da visão de língua como CAS.

É na terceira coleta, no entanto, que se podem observar os valores mais altos de duração absoluta do sistema vocálico do participante deste estudo, representado pelas células em amarelo. Esses valores, ademais, mostram uma aproximação aos obtidos pelos

\footnotetext{
${ }^{8}$ Para a obtenção da duração relativa, foi necessário a distinção entre palavras dissilábicas e trissilábicas.
} 
monolíngues porto-alegrenses, apresentados em Pereyron (2017), fato que indica que o sistema do aprendiz está em pleno desenvolvimento em direção às durações do sistema alvo, além de evidências de que a instrução na L3 tenha sido eficaz. Os valores de duração absoluta do participante do estudo longitudinal, na terceira coleta, se aproximam consideravelmente dos de duração absoluta dos monolíngues porto-alegrenses, sobretudo no caso das vogais [a] $(198,12 \mathrm{~ms}),[\varepsilon](195,2 \mathrm{~ms})$, [e] $(175,13 \mathrm{~ms})$, [i] (145,6 ms), [o] $(172,23 \mathrm{~ms})$ e [u] (146,9 ms). A duração absoluta da vogal [0] do participante não parece ainda se assemelhar à dos monolíngues porto-alegrenses, que apresentam valor de 204,9 ms, justamente a vogal mais longa do par [o] e [つ], cujo contraste em termos de F1 e F2 não parece ter sido adquirido pelo participante do estudo longitudinal ${ }^{9}$. Esses resultados, referentes a terceira coleta, fortalecem a evidência de que esse período foi marcado por um momento de mudança no sistema por parte do informante, tanto em termos de formantes quanto em termos de duração, de modo a demonstrar não somente a distinção entre as alturas das vogais médias anteriores, como também um alongamento em todas as vogais do português. Além disso, ainda que nas quarta e quinta coletas os valores referentes à duração absoluta sejam mais baixos do que aqueles encontrados na terceira coleta, eles tendem a ser mais altos do que aqueles encontrados no período pré-instrucional, sobretudo no caso das vogais médias-baixas.

Esses achados sugerem que o aprendiz mexicano (que emprega durações quase tão altas quanto às dos nativos brasileiros já na terceira coleta) parece empregar valores de durações intermediárias, possivelmente devido às interações entre os três sistemas do aprendiz. As durações absolutas do aprendiz, sobretudo na terceira coleta, parecem carregar padrões de duração do sistema de língua inglesa, que também dispõe de vogais longas, como também da própria L1, que dispõe de vogais mais curtas do que o português (SANTOS, 2014; SANTOS; RAUBER, 2016). Tal ocorrência se encontra em plena consistência com a ótica de língua como CAS, que prevê a emergência através das interações de estruturas linguísticas, e não a soma delas. Além disso, a ascensão gradiente dos valores da primeira coleta à terceira, bem como o recuo a partir de tal coleta, confirmam o caráter não-linear dos sistemas adaptativos complexos. Cabe por ora ressaltar que, apesar desse recuo, os valores da quinta coleta são maiores do que os da primeira coleta.

Em suma, as durações do sistema vocálico do português do participante deste estudo demonstram uma curva inicialmente ascendente, isto é, os valores aumentam conforme a exposição/imersão do sistema alvo e ao período de instrução formal com referência às vogais do português, que são mais longas do que as do sistema materno, conforme já mencionado, e atingem o pico mais alto na terceira coleta. Após este momento, os valores

9 Conforme mostra Pereyron (2017). 
mostraram uma redução quanto à duração vocálica, um momento marcado por grande instabilidade.

Assim como os valores de duração absoluta, os valores referentes à duração relativa da terceira coleta se apresentam como os mais altos, de modo a se assemelhar aos valores das durações relativas dos monolíngues porto-alegrenses (PEREYRON, 2017). Apesar de que as durações absolutas e relativas tendam a expressar as mesmas tendências, as relativas parecem fornecer mais evidências para o fato de que a duração vocálica empregada pelo participante mexicano se encontra muito próxima às porcentagens dos nativos porto-alegrenses.

Há uma semelhança nas curvas desenvolvimentais do sistema do português com o do inglês do referido participante (cf. seção a seguir), o que corrobora fortemente a premissa de interconexão e inter-relação entre os sistemas, conforme sugerem os adeptos à TSD e à Teoria da Complexidade (LARSEN-FREEMAN, 1997, 2011; JESSNER, 2008; DE BOT; LOWIE; VERSPOOR, 2007; ELLIS, 2011; LIMA JÚNIOR, 2016a, b; BLANK, 2016). A seguir, será descrita a próxima língua do participante deste estudo, o inglês (L2), que também será verificada em termos de durações absolutas e relativas. A partir da premissa expressa acima, espera-se que, pela instrução das vogais abertas no português (L3), as vogais abertas do sistema de L2 sofram alterações devido à completa interconexão dos sistemas fonético-fonológicos deste falante multilíngue.

\section{2 $O$ inglês}

$\mathrm{O}$ aluno deste estudo também é falante de inglês e possui nível B1 de proficiência em língua inglesa, comprovado pelo Oxford Online Placement Test ${ }^{10}$, realizado para fins deste estudo. $\mathrm{O}$ aprendiz relatou nunca ter cursado aulas de instrução formal de inglês, apenas algumas disciplinas da língua na escola, mas que seu primeiro contato com o idioma foi ao traduzir músicas para o espanhol, alguns anos antes deste estudo. Já na universidade, o aprendiz obteve bastante prática com a língua escrita, através da leitura de artigos acadêmicos.

A interconexão dos sistemas linguísticos do participante deste estudo, característica dos sistemas dinâmicos adaptativos complexos, parece ter agido sobre os valores de duração no sistema de L2 do aprendiz, assim com agiu no sistema de L3, o português (cf. descrito na seção anterior). Grosso modo, as vogais da L3, que apresentaram as durações mais longas na terceira coleta, são justamente as vogais que correspondem às da L2, que também foram alongadas na terceira coleta. As Tabelas 3 e 4, a seguir, apresentam as Médias e Desvios-Padrão dos valores de duração absoluta e relativa do sistema vocálico

${ }^{10}$ Maiores informações sobre o teste são encontradas em Purpura (2007). 
do inglês durante o período de instrução do português. As células em amarelo correspondem às realizações mais longas.

Tabela 3. Médias (em milissegundos) e Desvios-Padrão das durações absolutas das vogais do inglês produzidas pelo participante do estudo longitudinal (n. de cada vogal = 18 por coleta, exceto $[\varepsilon]$ com 15$)$

\begin{tabular}{|c|c|c|c|c|c|c|c|c|c|}
\hline Coleta & [a] & [æ] & {$[\Lambda]$} & {$[\varepsilon]$} & [i] & [I] & [0] & {$[\mathrm{u}]$} & [ひ] \\
\hline 1 & $\begin{array}{c}152,4 \\
D P: 31,1\end{array}$ & $\begin{array}{c}175,7 \\
\text { DP:31,9 }\end{array}$ & $\begin{array}{c}152,8 \\
\text { DP:30,6 }\end{array}$ & $\begin{array}{c}163,9 \\
\text { DP: } 33,6\end{array}$ & $\begin{array}{c}115,8 \\
\text { DP:36,1 }\end{array}$ & $\begin{array}{c}118,4 \\
\text { DP:34,1 }\end{array}$ & $\begin{array}{c}169,06 \\
\text { DP:38,1 }\end{array}$ & $\begin{array}{c}135,2 \\
D P: 25,4\end{array}$ & $\begin{array}{c}115,4 \\
D P: 25,4\end{array}$ \\
\hline 2 & $\begin{array}{c}164,3 \\
D P: 25,7\end{array}$ & $\begin{array}{c}195,2 \\
\text { DP:29,3 }\end{array}$ & $\begin{array}{c}173,8 \\
\text { DP: } 38,8\end{array}$ & $\begin{array}{c}184,2 \\
\text { DP:32,0 }\end{array}$ & $\begin{array}{c}138,9 \\
\text { DP:37,95 }\end{array}$ & $\begin{array}{c}137,3 \\
\text { DP:41,2 }\end{array}$ & $\begin{array}{c}195,1 \\
\text { DP:45,1 }\end{array}$ & $\begin{array}{c}150,9 \\
\text { DP:31,9 }\end{array}$ & $\begin{array}{c}133,2 \\
\text { DP:32,7 }\end{array}$ \\
\hline 3 & $\begin{array}{c}170,9 \\
D P: 27,8\end{array}$ & $\begin{array}{c}202,9 \\
D P: 30,3\end{array}$ & $\begin{array}{c}169,7 \\
\text { DP:35,7 }\end{array}$ & $\begin{array}{c}191,6 \\
\text { DP:39,5 }\end{array}$ & $\begin{array}{c}147,6 \\
D P: 26,5\end{array}$ & $\begin{array}{c}140,4 \\
\text { DP:41,05 }\end{array}$ & $\begin{array}{c}216,2 \\
\text { DP:44,8 }\end{array}$ & $\begin{array}{c}153,3 \\
\text { DP:28,9 }\end{array}$ & $\begin{array}{c}134,8 \\
D P: 25,5\end{array}$ \\
\hline 4 & $\begin{array}{c}161,9 \\
\text { DP:31,0 }\end{array}$ & $\begin{array}{c}187,6 \\
\text { DP:31,8 }\end{array}$ & $\begin{array}{c}172,7 \\
\text { DP:25,2 }\end{array}$ & $\begin{array}{c}182,8 \\
\text { DP:30,7 }\end{array}$ & $\begin{array}{c}133,6 \\
\text { DP:25,4 }\end{array}$ & $\begin{array}{c}139,3 \\
\text { DP:43,0 }\end{array}$ & $\begin{array}{c}190,9 \\
\text { DP:33,3 }\end{array}$ & $\begin{array}{c}151,9 \\
\text { DP:41,1 }\end{array}$ & $\begin{array}{c}137,06 \\
\text { DP:20,5 }\end{array}$ \\
\hline 5 & $\begin{array}{c}180,6 \\
\text { DP: } 18,2\end{array}$ & $\begin{array}{c}195,56 \\
D P: 22,45\end{array}$ & $\begin{array}{c}171 \\
\text { DP:25,9 }\end{array}$ & $\begin{array}{c}178,9 \\
D P: 29,0\end{array}$ & $\begin{array}{c}138,8 \\
\text { DP:26,7 }\end{array}$ & $\begin{array}{c}145,3 \\
\text { DP:32,5 }\end{array}$ & $\begin{array}{c}195,9 \\
\text { DP:37,2 }\end{array}$ & $\begin{array}{c}157,6 \\
\text { DP:26,7 }\end{array}$ & $\begin{array}{c}146,8 \\
D P: 27,6\end{array}$ \\
\hline
\end{tabular}

Tabela 4. Médias (em porcentagens) das durações relativas das vogais do inglês produzidas pelo participante do estudo longitudinal (n. de cada vogal $=18$ por coleta, exceto $[\varepsilon] \operatorname{com} 15)$

\begin{tabular}{|c|c|c|c|c|c|c|c|c|c|}
\hline $\begin{array}{l}\text { Monos- } \\
\text { sílabos }\end{array}$ & {$[a]$} & [æ] & {$[\Lambda]$} & {$[\varepsilon]$} & [i] & [I] & [ว] & {$[\mathrm{u}]$} & {$[\mho]$} \\
\hline Coleta 1 & $\begin{array}{c}20,19 \\
\text { DP:2,6 }\end{array}$ & $\begin{array}{c}22,73 \\
\text { DP:2,0 }\end{array}$ & $\begin{array}{c}19,54 \\
D P: 1,4\end{array}$ & $\begin{array}{c}19,99 \\
\text { DP:2,4 }\end{array}$ & $\begin{array}{c}16,24 \\
\text { DP:1,4 }\end{array}$ & $\begin{array}{c}17,68 \\
D P: 2,4\end{array}$ & $\begin{array}{c}23,00 \\
D P: 2,3\end{array}$ & $\begin{array}{c}17,46 \\
D P: 2,3\end{array}$ & $\begin{array}{c}16,67 \\
\text { DP: } 1,2\end{array}$ \\
\hline Coleta 2 & $\begin{array}{c}20,49 \\
\text { DP:2,95 }\end{array}$ & $\begin{array}{c}24,14 \\
D P: 3,0\end{array}$ & $\begin{array}{c}22,76 \\
\text { DP: } 1,6\end{array}$ & $\begin{array}{c}22,87 \\
\text { DP: } 1,8\end{array}$ & $\begin{array}{c}18,31 \\
\text { DP:2,6 }\end{array}$ & $\begin{array}{c}20,42 \\
\text { DP: } 1,8\end{array}$ & $\begin{array}{c}24,85 \\
D P: 2,6\end{array}$ & $\begin{array}{c}20,16 \\
\text { DP:2,8 }\end{array}$ & $\begin{array}{c}17,77 \\
\text { DP:2,7 }\end{array}$ \\
\hline Coleta 3 & $\begin{array}{c}20,30 \\
\text { DP:2,1 }\end{array}$ & $\begin{array}{c}24,65 \\
\text { DP:3,4 }\end{array}$ & $\begin{array}{c}21,15 \\
\text { DP:4,1 }\end{array}$ & $\begin{array}{c}23,37 \\
\text { DP: } 1,5\end{array}$ & $\begin{array}{c}18,27 \\
\text { DP: } 1,1\end{array}$ & $\begin{array}{c}19,73 \\
\text { DP:2,1 }\end{array}$ & $\begin{array}{c}28,26 \\
\text { DP:2,7 }\end{array}$ & $\begin{array}{c}19,40 \\
\text { DP:2,7 }\end{array}$ & $\begin{array}{c}17,68 \\
\text { DP: } 1,7\end{array}$ \\
\hline Coleta 4 & $\begin{array}{c}19,66 \\
\text { DP:3,9 }\end{array}$ & $\begin{array}{c}22,63 \\
\text { DP: } 2,7\end{array}$ & $\begin{array}{c}20,95 \\
\text { DP: } 1,85\end{array}$ & $\begin{array}{c}21,57 \\
\text { DP: } 1,74\end{array}$ & $\begin{array}{c}16,99 \\
\text { DP: } 1,9\end{array}$ & $\begin{array}{c}20,07 \\
\text { DP:4,1 }\end{array}$ & $\begin{array}{c}24,43 \\
\text { DP: } 2,4\end{array}$ & $\begin{array}{c}19,07 \\
\text { DP:4,6 }\end{array}$ & $\begin{array}{c}17,20 \\
\text { DP: } 2,7\end{array}$ \\
\hline Coleta 5 & $\begin{array}{c}22,13 \\
\text { DP: } 1,9 \\
\end{array}$ & $\begin{array}{c}23,17 \\
\text { DP: } 1,8 \\
\end{array}$ & $\begin{array}{c}20,58 \\
\text { DP: } 1,8 \\
\end{array}$ & $\begin{array}{c}21,03 \\
\text { DP: } 1,8 \\
\end{array}$ & $\begin{array}{c}18,28 \\
\text { DP:3,0 }\end{array}$ & $\begin{array}{c}18,71 \\
\text { DP:2,3 }\end{array}$ & $\begin{array}{c}24,98 \\
\text { DP:2,7 }\end{array}$ & $\begin{array}{c}18,60 \\
\text { DP:3,1 }\end{array}$ & $\begin{array}{c}19,95 \\
\text { DP:2,6 }\end{array}$ \\
\hline $\begin{array}{l}\text { Dissí- } \\
\text { Labos }\end{array}$ & {$[a]$} & [æ] & {$[\Lambda]$} & {$[\varepsilon]$} & [i] & [I] & [0] & {$[\mathrm{u}]$} & {$[\widetilde{J}]$} \\
\hline Coleta 1 & $\begin{array}{c}12,71 \\
\text { DP: } 1,5\end{array}$ & $\begin{array}{c}15,49 \\
\text { DP: } 1,25 \\
\end{array}$ & $\begin{array}{c}12,91 \\
\text { DP: } 1,2 \\
\end{array}$ & $\begin{array}{c}13,46 \\
\text { DP: } 1,7\end{array}$ & $\begin{array}{c}8,64 \\
\text { DP:2,2 } \\
\end{array}$ & $\begin{array}{c}9,19 \\
\text { DP: } 1,4 \\
\end{array}$ & $\begin{array}{c}13,38 \\
\text { DP: } 1,8\end{array}$ & $\begin{array}{c}11,68 \\
\text { DP: } 1,4\end{array}$ & $\begin{array}{c}10,14 \\
\text { DP: } 1,2\end{array}$ \\
\hline Coleta 2 & $\begin{array}{c}14,98 \\
\text { DP:2,2 }\end{array}$ & $\begin{array}{c}19,19 \\
D P: 2,45\end{array}$ & $\begin{array}{c}14,38 \\
D P: 2,5\end{array}$ & $\begin{array}{c}16,27 \\
\text { DP:1,5 }\end{array}$ & $\begin{array}{c}11,55 \\
\text { DP:2,5 }\end{array}$ & $\begin{array}{c}10,96 \\
\text { DP: } 1,7\end{array}$ & $\begin{array}{c}16,80 \\
\text { DP:3,0 }\end{array}$ & $\begin{array}{c}13,44 \\
\text { DP: } 1,1\end{array}$ & $\begin{array}{c}12,89 \\
\text { DP:2,0 }\end{array}$ \\
\hline Coleta 3 & $\begin{array}{c}15,71 \\
\text { DP:2,4 }\end{array}$ & $\begin{array}{c}19,05 \\
\text { DP: } 1,6\end{array}$ & $\begin{array}{c}15,32 \\
\text { DP: } 1,5\end{array}$ & $\begin{array}{c}15,74 \\
\text { DP: } 1,3\end{array}$ & $\begin{array}{c}13,28 \\
\text { DP: } 1,65\end{array}$ & $\begin{array}{c}10,85 \\
\text { DP: } 1,6\end{array}$ & $\begin{array}{c}18,15 \\
\text { DP: } 1,5\end{array}$ & $\begin{array}{c}13,97 \\
\text { DP: } 1,7\end{array}$ & $\begin{array}{c}12,47 \\
\text { DP: } 1,5\end{array}$ \\
\hline Coleta 4 & $\begin{array}{c}15,18 \\
D P: 2,3\end{array}$ & $\begin{array}{c}17,36 \\
\text { DP: } 1,4\end{array}$ & $\begin{array}{c}16,26 \\
\text { DP: } 1,8\end{array}$ & $\begin{array}{c}15,17 \\
\text { DP: } 1,2\end{array}$ & $\begin{array}{c}12,09 \\
\text { DP:2,4 }\end{array}$ & $\begin{array}{c}11,10 \\
D P: 2,6\end{array}$ & $\begin{array}{c}16,47 \\
\text { DP: } 1,05\end{array}$ & $\begin{array}{c}13,85 \\
\text { DP:0,96 }\end{array}$ & $\begin{array}{c}14,09 \\
\text { DP: } 1,36\end{array}$ \\
\hline Coleta 5 & $\begin{array}{c}16,27 \\
D P: 1,1\end{array}$ & $\begin{array}{c}18,30 \\
D P: 1,3\end{array}$ & $\begin{array}{c}15,67 \\
\text { DP: } 1,7\end{array}$ & $\begin{array}{c}15,30 \\
\text { DP: } 1,3\end{array}$ & $\begin{array}{c}12,22 \\
\text { DP: } 1,3\end{array}$ & $\begin{array}{c}12,69 \\
D P: 2,5\end{array}$ & $\begin{array}{c}16,33 \\
\text { DP: } 1,2\end{array}$ & $\begin{array}{c}13,95 \\
\text { DP: } 1,2\end{array}$ & $\begin{array}{c}13,26 \\
D P: 0,85\end{array}$ \\
\hline
\end{tabular}


Os valores apresentados nas Tabelas 3 e 4 mostram uma tendência semelhante à L3 (português) em termos de duração da L2 (inglês): a terceira e a quinta coleta são as que dispõem de valores mais altos, o que representa uma maior duração vocálica, mas os valores encontram-se em flutuação e não apresentam uma gradiente ascensão. No caso do inglês, o participante realiza as vogais de forma mais alongada na segunda, terceira e quinta coletas.

Similarmente aos resultados referentes à duração absoluta encontrados no português do participante, a primeira coleta é a que dispõe dos valores mais baixos. Mesmo a segunda coleta, cujos valores, ainda que mais altos, são mais baixos do que os encontrados na terceira e na quinta coleta, apresenta valores mais altos do que as vogais do português deste aprendiz, de modo a indicar que o sistema vocálico do inglês dispõe de durações maiores do que o seu sistema de L3. Além disso, o período após a terceira coleta, que mostrou desestabilização do sistema em termos de eixos de F1 e de F2 (cf. PEREYRON, 2017), apresenta as vogais nas suas mais alongadas realizações, em ambas as línguas. $\mathrm{Na}$ $\mathrm{L} 2$, as vogais médias anteriores, como nas palavras 's[c]t' e 'c[æ]t, e a média posterior, como na palavra 'c[ว]ffin', atingem suas maiores durações na terceira coleta, e o mesmo ocorre na L3: a média anterior aberta, como em 'qu[ع]pe', e a média posterior aberta, como em 'c[ग]po', apresentam as maiores durações neste momento do desenvolvimento do aprendiz. Já a vogal [a] da L2 apresenta a maior duração na quinta coleta, seguida da terceira coleta, justamente nas duas etapas do desenvolvimento do aprendiz em que a referida vogal mostra maior aproximação, em termos de F1, da vogal [ $]$.

Dessa forma, a instrução referente às vogais abertas do português parece ter influenciado não somente as durações das vogais abertas do próprio português, mas também as do inglês do participante trilíngue. As vogais abertas do sistema da L2 parecem ter sido desestabilizadas justamente no momento em que novas categorias foram formadas na L3 e, pela inter-relação entre os espaços acústicos do participante, as durações parecem ter sofrido efeitos de alongamento exatamente neste período de caos.

Os valores apresentados nas Tabelas 3 e 4 representam, mais uma vez, a não-linearidade, uma propriedade dos sistemas caóticos e dos sistemas complexos, uma vez que, ao observarmos os valores das coletas 1 a 5 , percebemos que as durações absolutas não tendem a mostrar alteração crescentemente, mas aumentam da coleta 1 a 2 apenas. Depois da terceira coleta, as vogais mostram oscilações em termos de valores de duração, de modo a não apresentar comportamento linear. De acordo com Chan (2001), a complexidade emerge da inter-relação, interação e da interconectividade dos elementos do sistema e entre o sistema e seu ambiente. Tal fato implica que uma ação de uma das partes do sistema 
influenciará todas as outras partes relacionadas, e não de uma maneira uniforme, o que representa o caráter não-linear desses sistemas. Chan (2001) também sugere que sistemas complexos exploram o seu espaço de possibilidades e criam novos padrões de relações. Tais sistemas funcionam melhor quando combinam ordem e caos em uma medida apropriada: estabilidade e instabilidade andam juntas e, conforme Larsen-Freeman (1997) afirma, a sistemacidade e a variabilidade não desafiam uma à outra, elas se alimentam.

Em síntese, a instrução formal com foco na articulação das vogais médias altas e médias baixas do português parece ter exercido influência tanto no sistema-alvo (L3), quanto no sistema de L2 do participante deste estudo, sobretudo com referência às vogais médias baixas anteriores (em termos de frequências e duração vocálica) e às vogais médias posteriores (em termos de duração vocálica). Há evidências para acreditar que, a partir da terceira coleta, que apresenta valores formânticos e de duração máximos, uma alteração em um sistema linguístico pôde alterar o outro, provavelmente devido a esse ponto culminante encontrado neste período do desenvolvimento, que, de tão alterado, parece afetar, também, a outra língua.

Tomaram-se por base teórica os autores adeptos à TSD e à Teoria da Complexidade, que argumentam a favor da interconexão entre os sistemas, bem como do fato de que as línguas do falante multilíngue pertencem a um mesmo sistema psicolinguístico. Tais aspectos levam, de fato, a influências múltiplas entre as línguas. Desse modo, a hipótese que regeu o estudo longitudinal até este ponto de análise foi confirmada em termos de alterações na L2 transferidas da L3. Cabe ainda investigar se essas alterações também exercem influências na L1 do participante, o espanhol.

A seguir, será apresentada a análise do sistema linguístico materno do participante deste estudo, a variedade mexicana de espanhol.

\subsection{O espanhol}

Quanto às durações das vogais do espanhol durante as cinco coletas, a duração absoluta das cinco vogais mostrou-se alterada, sendo essas realizadas mais brevemente nas duas primeiras coletas e mais alongadas nas duas últimas coletas, de modo a indicar que a instrução oferecida ao aluno (juntamente com outras variáveis, como o próprio contexto de imersão no português) possa ter exercido influência na duração vocálica do sistema materno. Tal ocorrido está em consonância com a premissa defendida neste trabalho, de que a transferência vocálica pode ocorrer da língua menos dominante em direção à língua mais dominante, isto é, a materna. Esses resultados corroboram os argumentos apontados por Grosjean (2013), que afirmam que a transferência é, no mínimo, bidirecional. A 
Tabela 5 a seguir expõe os valores referentes à duração absoluta das vogais do espanhol do participante e a Tabela 6, os valores referentes à duração relativa. As células em amarelo correspondem às durações mais longas.

Tabela 5. Médias (em milissegundos) e Desvios-Padrão (DP) das durações absolutas das vogais do espanhol produzidas pelo participante do estudo longitudinal (n. de cada vogal $=18$ por coleta, total de 90 por coleta)

\begin{tabular}{c|c|c|c|c|c}
\hline & {$[\mathrm{a}]$} & {$[\mathrm{e}]$} & {$[\mathrm{i}]$} & {$[\mathrm{o}]$} & {$[\mathrm{u}]$} \\
\hline \multirow{2}{*}{ Coleta 1 } & 110,55 & 102,33 & 74,16 & 112,38 & 93,16 \\
& $\mathrm{DP}: 15,9$ & $\mathrm{DP}: 16,0$ & $\mathrm{DP}: 10,7$ & $\mathrm{DP}: 18,7$ & $\mathrm{DP}: 15,3$ \\
\hline \multirow{2}{*}{ Coleta 2 } & 110,83 & 83,22 & 68,83 & 104,77 & 80,55 \\
& $\mathrm{DP}: 8,5$ & $\mathrm{DP}: 9,1$ & $\mathrm{DP}: 12,1$ & $\mathrm{DP}: 9,9$ & $\mathrm{DP}: 13,95$ \\
\hline \multirow{2}{*}{ Coleta 3 } & 123,5 & 106,72 & 84,44 & 129,22 & 103,27 \\
& $\mathrm{DP}: 17,4$ & $\mathrm{DP}: 18,1$ & $\mathrm{DP}: 10,5$ & $\mathrm{DP}: 13,2$ & $\mathrm{DP}: 12,7$ \\
\hline \multirow{2}{*}{ Coleta 4 } & 115,38 & 108,72 & 91,5 & 127,94 & 105,66 \\
& $\mathrm{DP}: 19,2$ & $\mathrm{DP}: 18,7$ & $\mathrm{DP}: 11,2$ & $\mathrm{DP}: 14,2$ & $\mathrm{DP}: 16,8$ \\
\hline \multirow{2}{*}{ Coleta 5 } & 142,55 & 124,94 & 97,88 & 147,38 & 118,88 \\
& $\mathrm{DP}: 14,15$ & $\mathrm{DP}: 14,5$ & $\mathrm{DP}: 18,7$ & $\mathrm{DP}: 19,45$ & $\mathrm{DP}: 22,2$ \\
\hline
\end{tabular}

Tabela 6. Médias (em porcentagens) e Desvios-Padrão (DP) das durações relativas das vogais do espanhol produzidas pelo participante do estudo longitudinal (n. de cada vogal $=18$ por coleta, total de 90 por coleta)

\begin{tabular}{c|c|c|c|c|c}
\hline Dissílabos & {$[\mathrm{a}]$} & {$[\mathrm{e}]$} & {$[\mathrm{i}]$} & {$[\mathrm{o}]$} & {$[\mathrm{u}]$} \\
\hline \multirow{2}{*}{ Coleta 1} & 13,69 & 12,74 & 8,83 & 13,70 & 12,37 \\
& $\mathrm{DP}: 2,5$ & $\mathrm{DP}: 2,5$ & $\mathrm{DP}: 1,3$ & $\mathrm{DP}: 2,1$ & $\mathrm{DP}: 1,7$ \\
\hline \multirow{2}{*}{ Coleta 2 } & 14,45 & 10,31 & 9,04 & 13,31 & 11,14 \\
& $\mathrm{DP}: 1,1$ & $\mathrm{DP}: 1,1$ & $\mathrm{DP}: 1,0$ & $\mathrm{DP}: 1,3$ & $\mathrm{DP}: 1,5$ \\
\hline \multirow{2}{*}{ Coleta 3 } & 15,99 & 13,02 & 9,63 & 15,63 & 12,72 \\
& $\mathrm{DP}: 1,2$ & $\mathrm{DP}: 2,3$ & $\mathrm{DP}: 1,05$ & $\mathrm{DP}: 1,3$ & $\mathrm{DP}: 1,2$ \\
\hline \multirow{2}{*}{ Coleta 4 } & 15,65 & 14,42 & 11,76 & 16,33 & 13,66 \\
& $\mathrm{DP}: 1,4$ & $\mathrm{DP}: 2,0$ & $\mathrm{DP}: 1,5$ & $\mathrm{DP}: 1,3$ & $\mathrm{DP}: 1,85$ \\
\hline \multirow{2}{*}{ Coleta 5 } & 16,97 & 14,98 & 11,84 & 17,19 & 15,04 \\
& $\mathrm{DP}: 0,82$ & $\mathrm{DP}: 1,7$ & $\mathrm{DP}: 2,5$ & $\mathrm{DP}: 2,3$ & $\mathrm{DP}: 1,5$ \\
\hline \multirow{2}{*}{ Trissílabos } & {$[\mathrm{a}]$} & {$[\mathrm{e}]$} & {$[\mathrm{i}]$} & {$[\mathrm{o}]$} & {$[\mathrm{u}]$} \\
\hline \multirow{2}{*}{ Coleta 1 } & 11,25 & 10,66 & 7,81 & 11,89 & 8,79 \\
& $\mathrm{DP}: 1,5$ & $\mathrm{DP}: 1,6$ & $\mathrm{DP}: 1,3$ & $\mathrm{DP}: 2,4$ & $\mathrm{DP}: 2,0$ \\
\hline \multirow{2}{*}{ Coleta 2 } & 11,91 & 9,65 & 7,64 & 11,34 & 7,88 \\
& $\mathrm{DP}: 0,85$ & $\mathrm{DP}: 0,9$ & $\mathrm{DP}: 1,7$ & $\mathrm{DP}: 1,3$ & $\mathrm{DP}: 1,5$ \\
\hline \multirow{2}{*}{ Coleta 3 } & 12,02 & 10,98 & 9,50 & 13,27 & 10,21 \\
& $\mathrm{DP}: 1,5$ & $\mathrm{DP}: 1,8$ & $\mathrm{DP}: 1,35$ & $\mathrm{DP}: 1,6$ & $\mathrm{DP}: 1,5$ \\
\hline \multirow{2}{*}{ Coleta 4 } & 11,56 & 10,49 & 9,36 & 13,52 & 10,58 \\
& $\mathrm{DP}: 1,9$ & $\mathrm{DP}: 1,65$ & $\mathrm{DP}: 1,4$ & $\mathrm{DP}: 1,3$ & $\mathrm{DP}: 1,6$ \\
\hline \multirow{2}{*}{ Coleta 5 } & 13,94 & 12,39 & 9,90 & 15,15 & 10,80 \\
& $\mathrm{DP}: 1,45$ & $\mathrm{DP}: 1,4$ & $\mathrm{DP}: 1,5$ & $\mathrm{DP}: 2,1$ & $\mathrm{DP}: 2,3$ \\
\hline
\end{tabular}


As durações apresentadas nas Tabelas 5 e 6 anteriores, no que diz respeito a primeira e a segunda coleta, sofrem uma diminuição nos valores, com exceção da vogal baixa [a], que, na segunda coleta, apresenta uma média de duração muito próxima à da primeira coleta. As durações das demais vogais diminuem consideravelmente entre a primeira e a segunda coleta, possivelmente devido a um período de instabilidade do sistema, já que a segunda coleta ocorreu após apenas 4 sessões de instrução do português. Tal fato pode ser interpretado como se o sistema vocálico da L1, com a intensificação da L3, estivesse entrando em um estado de caos, característico dos sistemas dinâmicos adaptativos complexos.

No restante das coletas, as durações absolutas das vogais do espanhol sofrem um aumento gradual, o que provavelmente tenha ocorrido pela exposição ao português bem como à instrução acelerada, da mesma forma que ocorreu com as durações dos sistemas maternos dos participantes residentes no Brasil do estudo transversal. Esse ocorrido está em consistência com a premissa dinâmica de que qualquer alteração pode alterar o restante do(s) sistema(s), e ainda com a afirmação de Bybee (2010), de que o contexto e a frequência de uso das palavras são fortes condicionadores para o detalhe fonético. A autora, ademais, sugere que a repetição do input a que o aprendiz é exposto, ou seja, a frequência com que as palavras individuais ou sequências são empregadas, afeta a representação mental, e, nesse sentido, o uso da língua inclui, além do processamento, os usos e as interações sociais.

Cabe ainda ressaltar que, ao observarmos os valores da quinta coleta na Tabela 5 anterior, as durações vocálicas do participante na L1 são idênticas, ou pelo menos muito próximas, às durações da primeira coleta da L3 (português), conforme apresentado na Tabela 1 anterior: o aprendiz apresenta uma média de 142,9 ms para [a]; 125,7 ms para [e]; 97,2 ms para [i]; 135,5 para [o]; e 117,2 ms para [u]. Essas semelhanças mostram que a duração mais longa do participante na L1 (quinta coleta) corresponde à duração mais curta de que ele dispõe na L3 (primeira coleta, período pré-instrução). Esse achado indica que, mesmo antes da instrução, o informante já produzia, na L3, uma vogal mais longa do que aquela da sua L1 (possivelmente em função da exposição à fala de Porto Alegre), e essas vogais ficaram ainda mais longas com a instrução. Nesse sentido, essas "alterações" na duração das vogais da L1 do participante apresentam um valor intermediário, que não correspondem à duração do português, tampouco à do espanhol. Esses valores correspondem às durações que o participante tinha na L3 antes da instrução. Assim, a instrução parece conduzir o aprendiz a aumentar seus valores de duração na L3 e, também, na L1. 
Porém, na L1, esse aumento se dá até um ponto definido, que corresponde à duração que tal aprendiz tinha na L3, antes da instrução (que, por sua vez, já era uma categoria híbrida). Além disso, os valores mais longos na L1, mesmo antes da instrução da L3, são provavelmente resultado da exposição do aprendiz ao português, língua do país em que ele vive, e essa exposição contínua já havia causado alguma modificação na língua-materna antes mesmo do período de instrução.

Finalmente, o período de maior instabilidade (que corresponde à terceira coleta, em que se podem observar diversas alterações nos sistemas do informante) parece ter exercido, mesmo que mais amenamente, efeitos sobre a duração das vogais do sistema materno, pelo menos em relação à [a] e à [o]. Conforme já discutido, as vogais do sistema materno apresentaram as maiores durações na quinta coleta, momento em que o participante já se encontrava no Brasil há um semestre e havia participado de todas as sessões da instrução formal. No entanto, foi na terceira coleta que as vogais [a] e [o] apresentaram as durações mais altas, depois da quinta coleta. Devido à interconexão entre os sistemas, a desestabilização do sistema de L3 do aprendiz parece ter sido transferida para todos os outros aspectos por nós investigados.

\section{Conclusão}

Com base nos resultados descritos, no que concerne ao desenvolvimento da L2 e da L3 do participante deste estudo, há uma considerável inter-relação entre os sistemas, além da interconexão que a L2 e a L3 mostraram com a L1. Há bastante variabilidade nos valores, o que é esperado, dentro do arcabouço teórico utilizado nesta pesquisa, devido, entre diversos fatores, à não-linearidade dos sistemas complexos. A variabilidade possivelmente deriva do desenvolvimento acelerado causado pela instrução intensiva, o que sugere que o processo de desenvolvimento linguístico constitui, de fato, um sistema dinâmico adaptativo complexo. Os valores de duração da terceira coleta na língua de instrução mostraram-se bastante distintos dos demais, o que sugere o caráter não-linear no processo de desenvolvimento vocálico, uma propriedade da TSD e da Teoria da Complexidade. Os valores encontrados na terceira coleta da L3, ademais, parecem refletir um momento de desestabilização do sistema que se reflete, também, na L2 do aprendiz.

A L1 do participante também se mostrou alterada, de modo que é possível sugerir que a transferência entre os sistemas linguísticos também pode ocorrer da língua mais recente à língua mais entrincheirada. Considerando uma perspectiva dinâmica e complexa, esta pesquisa fundamenta-se na pressuposição de que é necessário rejeitar a noção unidi- 
recional de transferência linguística. A partir de tais resultados, pôde-se afirmar que uma L2 deve ser considerada como um sistema híbrido, que carrega características tanto da L1 quanto da L3. A L3, sob essa perspectiva, carrega aspectos das L1 e da L2. Além disso, a própria L1, ainda que de forma mais moderada, sofre influência dos outros sistemas que se estabelecem neste espaço fonológico comum. É rejeitada, portanto, a noção de direção singular quanto à transferência das L1 e L2 na L3, de modo que se possa assumir, assim, uma transferência multidirecional.

\section{Referências}

ALVES, M. A. Estudo dos parâmetros acústicos relacionados à produção das plosivas do Português Brasileiro na fala adulta: análise acústico-quantitativa. Tese (Doutorado em Letras). Florianópolis: Universidade Federal de Santa Catarina, 2015.

BARBOZA, C. L. F. Efeitos da Palatalização das Alveolares do Português Brasileiro no Percurso de Construção do Inglês como Língua Estrangeira. Tese (Doutorado em Letras). Fortaleza: Universidade Federal do Ceará, 2013.

BECKNER, C.; BLYTHE, R.; BYBEE, J.; CHRISTIANSEN, M.; CROFT, W.; ELLIS, N.; HOLLAND, J.; KE, J.; LARSEN-FREEMAN, D.; SCHOENEMANN, T. Language is a Complex Adaptive System: Position Paper. Language Learning, 59 (1), 2009 p. 1-26.

BLANK, C. A. A influência grafo-fônico-fonológica na produção oral e no processamento de priming em multilíngues: uma perspectiva dinâmica. Tese (Doutorado em Letras). Pelotas: Universidade Católica de Pelotas, 2013.

. A transferência grafo-fônico-fonológica em multilíngues falantes de português, espanhol, e inglês: uma abordagem dinâmica. In: ALVES, U. K. (Org.). Aquisição FonéticoFonológica de Língua Estrangeira: Investigações Rio-Grandenses e Argentinas em Discussão. Campinas, SP: Pontes Editores, 2016, p. 209-228.

BOERSMA, P.; WEENINK, D. Praat, Versão 5.4.08. Disponível em: http://www.praat. org. Acesso em: 9 nov. 2017.

BRITO, K. S. Influências interlinguísticas namente multilíngue: perspectivas psicolinguísticas e (psico)tipológicas. Tese (Doutorado em Letras). Curitiba: Universidade Federal do Paraná, 2011.

BYBEE, J. Language, usage and cognition. Cambridge: Cambridge University Press, 2010.

CELCE-MURCIA, M.; BRINTON, D. M.; GOODWIN, J. M. Teaching pronunciation: a reference for teachers of English to speakers of other languages. Nova Iorque: Cambridge University Press, 1996.

CENOZ, J. The Effect of Linguistic Distance, L2 Status and Age on Cross-lingustic Influence in Third Language Acquisition. In: CENOZ, J.; HUFEISEN, B.; JESSNER, U. (Ed.). Cross-linguistic Influence in Third Language Acquisition: Psycholinguistic Perspectives. Bristol: Multilingual Matters, 2001, p. 8-20. 
CHAN, S. Complex Adaptive Systems. Disponível em: http://web.mit.edu/esd.83/www/ notebook/Complex\%20Adaptive\%20Systems.pdf. Acesso em: 21 fev. 2019.

DE BOT, K. Introduction: Second Language Development and a Dynamic Process. The Modern Language Journal, v. 92, n. ii, p. 166-178, 2008.

; LOWIE, W.; VERSPOOR, M. A Dynamic System Theory approach to second language acquisition. Bilingualism: Language and Cognition, v. 10, n. 1, p. 7-21, 2007.

; LARSEN-FREEMAN, D. Researching second language development from a dynamic systems perspective. In: VERSPOOR, M. H.; DE BOT, K.; LOWIE, W. (Ed.). A Dynamic Approach to Second Language Development: Methods and Techniques. Amsterdam: John Benjamins Publishing Company, 2011, p. 5-24.

; LOWIE, W.; THORNE, S. L.; VERSPOOR, M. Dynamic System Theory as a comprehensive theory of second language development. In: P. García Mayo, J. Gutierrez Mangado, \& M. Martínez Adrián (Ed.). Contemporary perspectives on second language acquisition. John Benjamins Publishers, 2013, p. 167-189.

ELLIS, N. C. The Emergence of Language as a Complex Adaptive System. In: SIMPSON, J. (Ed.). Routledge Handbook of Applied Linguistics. Londres: Routledge / Taylor Francis, 2011, p. 654-667.

FEIDEN, J. A.; PEROZZO, R. V.; FINGER, I.; FONTES, A.B.A.L. Percepção de vogais médias altas e médias baixas do português brasileiro por falantes de espanhol rioplatense em tarefa de discriminação categórica. In: ALVES, U. K. (Org.). Aquisição FonéticoFonológica de Língua Estrangeira: Investigações Rio-Grandenses e Argentinas em Discussão. Campinas, SP: Pontes Editores, 2016, p. 85-103.

FRANCESCHINI, R. Sprachadoption: der Einfluss von Minderheitensprachen auf die Mehrheit, oder: Welche Kompetenzen der Minderheitensprachen haben Minderheitensprachen? Bulletin Suisse de Linguistique Appliquée, v. 69, n. 2, p. 137-153, 1999.

GROSJEAN, F. Bilingualism: a Short Introduction. In: GROSJEAN, F.; LI, P. The psycholinguistics of Bilingualism. Londres: Wiley-Blackwell, 2013, p. 13-31.

HERDINA, P.; JESSNER, U. A Dynamical Model of Multilingualism: Perspectives of Change in Psycholinguistics. Trowbridge: Cromwell Press Ltd., 2002.

JESSNER, U. Teaching third languages: Findings, trends and challenges. Language teaching, v. 41, n. 1, p. 15-56, 2008.

LARSEN-FREEMAN, D. Chaos/complexity science and second language acquisition. Applied linguistics, v. 18, n. 2, p. 141-165, 1997.

. The emergence of complexity, fluency, and accuracy in the oral and written production of five Chinese learners of English. Applied linguistics, v. 27, n. 4, p. 590-619, 2006.

- Complex, dynamic systems: A new transdisciplinary theme for applied linguistics? Language Teaching, v. 45, n. 2, p. 202-214, 2012. 
. Complexity theory: a new way to think. Revista Brasileira de linguística aplicada, v. 13, n. 2, p. 369-373, 2013. Disponível em: http://dx.doi.org/10.1590/S198463982013000200002 . Acesso em: 5 jun. 2016.

; CAMERON, L. Complex Systems and Applied Linguistics. Oxford: Oxford University Press, 2008.

LIMA JR., R. M. A necessidade de dados individuais e longitudinais para análise do desenvolvimento fonológico de 12 como sistema complexo. ReVEL, v. 14, n. 27, p. 203225, 2016 a.

LIMA JR, Ronaldo M. Análise longitudinal de vogais do inglês-L2 de brasileiros. GradusRevista Brasileira de Fonologia de Laboratório, v. 1, n. 1, p. 145-176, 2016 b.

LINDBLOM, B. Phonetic universals in vowel systems. In: OHALA, J..; JAEGER, J. (Ed.). Experimental Phonology. Florida: Academic Press, 1986, p 13-44.

PEREYRON, L. A produção vocálica por falantes de Espanhol (L1), Inglês (L2) e Português (L3): uma perspectiva dinâmica na (multi)direcionalidade da transferência linguística. Tese (Doutorado em Letras). Porto Alegre: Universidade Federal do Rio Grande do Sul, 2017.

PURPURA, J. Conceptualizing and measuring meaning in SLA Research, Second Language Research Forum (SLRF), University of Illinois, Champaign-Urbana. 2007. Disponível em http:// oxford.britanica-edu.org. Acesso em: 6 ago. 2016.

SANTOS, G. Percepção e produção das vogais médias do espanhol por falantes do português brasileiro. Tese (Doutorado em Letras). Pelotas: UCPEL, 2014.

; RAUBER, A. S. Percepção e produção das vogais médias do espanhol/LE. In: ALVES, U. K. (Org.). Aquisição Fonético-Fonológica de Língua Estrangeira: Investigações Rio-Grandenses e Argentinas em Discussão. Campinas: Pontes, 2016, p. 151-178.

SILVA, A. H. P. A variável tempo nos estudos de aquisição. In: BRAWERMAN-ALBINI, A; CASTRO GOMES, M. L. O jeitinho brasileiro de falar inglês. Pontes, 2014a. p. 33-47.

SILVA, A. H. P. Organização temporal de encontros vocálicos no Português Brasileiro e a relação entre Fonética e Fonologia. Letras de Hoje, v. 49, n. 1, p. 11-18, 2014 b.

VAN GELDER, T.; PORT, R. It's about time: an overview of the dynamics approach to Cognition. In: PORT, R.; VAN GELDER, T. (Ed.). Mind as Motion: Explorations in the Dynamics of Cognition. Cambridge: The MIT Press, 1995, p. 1- 43.

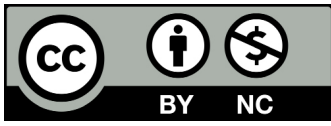

Data de submissão: 30/01/2018

Data de aceite: $18 / 11 / 2018$ 